\title{
Exploring the value of routinely collected herd data for estimating dairy cattle welfare
}

\author{
M. de Vries, ${ }^{\star 1}$ E. A. M. Bokkers, ${ }^{\star}$ G. van Schaik, † B. Engel,† T. Dijkstra,† and I. J. M. de Boer \\ *Animal Production Systems Group, Wageningen University, $6700 \mathrm{AH}$ Wageningen, the Netherlands \\ †GD Animal Health Service, 7400 AA Deventer, the Netherlands \\ ¥Biometris, Wageningen University, 6700 AC Wageningen, the Netherlands
}

\section{ABSTRACT}

Routine on-farm assessment of dairy cattle welfare is time consuming and, therefore, expensive. A promising strategy to assess dairy cattle welfare more efficiently is to estimate the level of animal welfare based on herd data available in national databases. Our aim was to explore the value of routine herd data (RHD) for estimating dairy cattle welfare at the herd level. From November 2009 through March 2010, 7 trained observers collected data for 41 welfare indicators in a selected sample of 183 loose-housed and 13 tethered Dutch dairy herds (herd size: 10 to 211 cows) using the Welfare Quality protocol for cattle. For the same herds, RHD relating to identification and registration, management, milk production and composition, and fertility were extracted from several national databases. The RHD were used as potential predictors for each welfare indicator in logistic regression at the herd level. Nineteen welfare indicators were excluded from the predictions, because they showed a prevalence below $5 \%$ (15 indicators), or were already listed as RHD (4 indicators). Predictions were less accurate for 7 welfare indicators, moderately accurate for 14 indicators, and highly accurate for 1 indicator. By forcing to detect almost all herds with a welfare problem (sensitivity of at least $97.5 \%$ ), specificity ranged from 0 to $81 \%$. By forcing almost no herds to be incorrectly classified as having a welfare problem (specificity of at least $97.5 \%$ ), sensitivity ranged from 0 to $67 \%$. Overall, the best-performing prediction models were those for the indicators access to at least 2 drinkers (resource based), percentage of very lean cows, cows lying outside the supposed lying area, and cows with vulvar discharge (animal based). The most frequently included predictors in final models were percentages of on-farm mortality in different lactation stages. It was concluded that, for most welfare indicators, RHD have value for estimating dairy cattle welfare. The RHD can

Received January 17, 2013.

Accepted October 12, 2013.

${ }^{1}$ Corresponding author: marion.devries@wur.nl serve as a prescreening tool for detecting herds with a welfare problem, but this should be followed by a verification of the level of welfare in an on-farm assessment to identify false-positive herds. Consequently, the number of farm visits needed for routine welfare assessments can be reduced. The RHD also hold value for continuous monitoring of dairy cattle welfare. Prediction models developed in this study, however, should first be validated in additional field studies.

Key words: animal welfare, herd data, monitoring, Welfare Quality

\section{INTRODUCTION}

Because farm animal welfare is high on political and societal agendas of many countries, pressure exists to establish welfare assurance programs in which farm animal welfare is routinely assessed. These programs require the use of on-farm animal welfare assessments, in which farms are visited and assessed against compliance with a set of animal welfare criteria. Routine on-farm assessment of dairy cattle welfare, however, is time consuming and, therefore, expensive (Knierim and Winckler, 2009; Blokhuis et al., 2010). This is especially true when on-farm assessments use mainly animalbased indicators, which are increasingly preferred over resource-based indicators because they are more closely linked to the welfare of animals (Webster et al., 2004). The Welfare Quality assessment protocol for dairy cattle, for example, in which the majority of indicators is animal based, takes about 4.4 to $7.7 \mathrm{~h}$ for herds of 25 to 200 cows (Welfare Quality, 2009). The time and consequent costs of on-farm assessment protocols may inhibit their use in welfare assurance programs.

A promising, more efficient strategy may be to estimate the level of animal welfare based on national herd databases, leading to a reduction in the number of onfarm assessments. Especially in developed countries, all kinds of data are routinely collected from dairy farms, relating, for example, to identification and registration, milk quality, productivity, and fertility. Various studies have shown univariable associations between these rou- 
tine herd data (RHD) and dairy cattle welfare indicators (WI; de Vries et al., 2011). Milk yield, for example, has been associated with body condition, water intake, lameness, integument alterations, social behaviors, and various indicators of disease (e.g., Steiger Burgos et al., 2001; Phillips and Rind, 2002; Bareille et al., 2003; Haskell et al., 2006; Bicalho et al., 2008; Roche et al., 2009). Therefore, RHD might provide a continuous, easy, and inexpensive opportunity to estimate the level of animal welfare on farms. Because WI are often associated with various RHD, it has been suggested that the potential of RHD for estimating dairy cattle welfare may increase when they are combined in multivariable analyses (de Vries et al., 2011). To determine its suitability for practical application, this potential should, therefore, be evaluated in an observational study at the herd level.

To our knowledge, only 2 studies have explored the value of RHD for estimating dairy cattle welfare in an observational study at the herd level, using multivariable analyses. Sandgren et al. (2009) used RHD to identify herds with poor welfare in 55 Swedish dairy herds. A herd was considered to have poor welfare if it was among the $10 \%$ worst-scoring herds for at least 2 of 9 animal-based indicators assessed. Based on the same data set, Nyman et al. (2011) aimed to identify herds with good welfare, which were herds that were not among the 10\% worst-scoring herds for any of the 9 animal-based indicators assessed. In both studies, sensitivity (Se) and specificity (Sp) were optimized, and used to evaluate performance of final prediction models. Sensitivity is the probability of correctly identifying a herd with poor welfare, whereas Sp is the probability of correctly identifying a herd with no poor welfare.

In our study, we included a larger number of dairy herds and more WI to evaluate the value of RHD for estimating dairy cattle welfare than Sandgren et al. (2009) and Nyman et al. (2011). We focused on the fact that a high Se, a high Sp, or an optimum value for both Se and Sp may be demanded in different decisionmaking contexts (Greiner et al., 2000). A high Se, for example, may be required when overlooking herds with poor welfare is considered unacceptable, whereas a high Sp may be demanded when costs of on-farm welfare assessments are a serious impediment. Optimizing both Se and Sp may be required if the purpose is to estimate welfare levels in a population for which the prevalence is unknown, or to monitor welfare over time. In these 3 contexts, RHD could be used as a prescreening, instantassessment, or monitoring tool, respectively. However, a trade-off exists between Se and Sp (Dohoo et al., 2009). The higher the proportion of herds that are correctly identified as having poor welfare (i.e., high Se), for example, the higher the proportion of herds that are incorrectly identified as having poor welfare (i.e., more false positives, thus low $\mathrm{Sp}$ ). These trade-offs must be evaluated to judge the value of RHD for different applications. Our aim, therefore, was to explore the value of RHD for estimating dairy cattle welfare at the herd level, by using different levels of Se and Sp.

\section{MATERIALS AND METHODS}

\section{Sources of RHD}

Both for herd selection and evaluation of their potential for estimating dairy cattle welfare, we used data from several national databases containing RHD relating to identification and registration, management, milk production, milk composition, and reproduction (Table 1). Data stored in these databases are routinely collected from Dutch dairy farms by the Dutch identification and registration (I\&R) system, the rendering plant, the milk quality assurance company (participation legally required), the animal health service, and the cattle improvement syndicate (voluntary participation). Sampling frequency at the farm varies from continuous (e.g., slaughter date) to approximately $4 \mathrm{wk}$ (e.g., individual milk yield), and registration is at the animal or the herd level, depending on the variable. These databases cover all Dutch dairy herds for most data, except for test-day milk recordings of the cattle improvement syndicate, which covers about $80 \%$ of all Dutch dairy herds.

\section{Herd Selection}

To properly evaluate the value of RHD for estimating dairy cattle welfare, we aimed for data from herds that span a wide range of levels of animal welfare. This wide range could be obtained by either visiting a large number of herds or by increasing the variation in the levels of welfare among herds. Because the number of farms that could be visited was limited, herds were selected to increase variation in the level of animal welfare. Because most WI and RHD were animal based, it was hypothesized that relations between WI and RHD would not much depend on the type of housing system. Therefore, herd selection was not restricted to a single type of housing system.

For approximately 5,000 herds in the RHD database participating in a health program of a Dutch dairy cooperative, we calculated a composite health score (CHS) between 0 (worst) and 50 (best). A CHS, for which RHD was used from January 2008 through June 2009 , consisted of 5 variables that were expected to be associated with animal welfare [based on de Vries et al. (2011)]: cow and young stock mortality, bulk tank 
Table 1. Categories, units, and sampling levels of routine herd data (RHD) at the original sampling level, and variables of RHD at the herd level

\begin{tabular}{|c|c|c|c|c|}
\hline Category & $\begin{array}{l}\text { RHD } \\
\text { (sampling level) }\end{array}$ & Unit & Level & RHD (herd level) \\
\hline \multirow[t]{3}{*}{ Identification and registration } & Birth & Date & Animal & \multirow{3}{*}{$\begin{array}{l}\text { Herd size (no. of cows), change in herd size }(\%) \text {, average age (mo), cows } \\
\text { older than } 5 \text { yr }(\%) \text {, cows <60 DIM }(\%) \text {, replacement }(\%) \text {, slaughter } \\
(\%) \text {, slaughter of cows }<210 \text { DIM (yes } / \text { no), on-farm mortality of cattle in } \\
\text { different age categories }(\%) \text {, on-farm mortality of cows in different lactation } \\
\text { stages (yes/no) }\end{array}$} \\
\hline & Slaughter & Date & Animal & \\
\hline & On-farm mortality & Date & Animal & \\
\hline \multirow[t]{5}{*}{ Management } & Type of housing $^{1}$ & Loose/tethered & Herd & \multirow{5}{*}{$\begin{array}{l}\text { Loose housing (yes/no), access to pasture (yes/no), herd biosecurity status } \\
\text { (open/closed), certified disease-free status for bovine viral diarrhea (BVD; } \\
\text { yes/no), infectious bovine rhinotracheitis (IBR; yes/no), Salmonella (yes/ } \\
\text { no) }\end{array}$} \\
\hline & Access to pasture $^{1}$ & Yes/no & Herd & \\
\hline & Herd biosecurity status & Open/closed & Herd & \\
\hline & Certified disease-free status & Yes/no & Herd & \\
\hline & Certified organic $^{1,2}$ & Yes/no & Herd & \\
\hline \multirow{4}{*}{ Milk production } & Yield & $\mathrm{kg} / \mathrm{d}$ & Herd & \multirow{4}{*}{$\begin{array}{l}\text { Average milk yield per cow/d }(\mathrm{kg}) \text {, net result }{ }^{3}(€) \text {, change in net result } \\
(\%) \text {, average DIM }\end{array}$} \\
\hline & Yield & $\mathrm{kg} / \mathrm{d}$ & Animal & \\
\hline & Predicted yield & $\mathrm{kg} / \mathrm{d}$ & Animal & \\
\hline & DIM & No. & Animal & \\
\hline \multirow[t]{11}{*}{ Milk composition } & Fat & $\%$ & Herd & \multirow{11}{*}{$\begin{array}{l}\text { Average fat }(\%) \text {, average protein }(\%) \text {, average urea }(\%) \text {, average proportion } \\
\text { fat/protein of cows } 0 \text { to } 60 \mathrm{DIM}, \mathrm{FFA}(\mathrm{mmol} / 100 \mathrm{~g}) \text {, butyric acid bacteria } \\
\text { (yes/no), bulk tank milk SCC (cells } / \mathrm{mL}) \text {, cows with udder infection }{ }^{4}(\%), \\
\text { cows with new udder infection }{ }^{4}(\%) \text {, heifers with udder infection }{ }^{4}(\%), \\
\text { average SCC of cows in different lactation stages (cells } / \mathrm{mL})\end{array}$} \\
\hline & Fat & $\%$ & Animal & \\
\hline & Protein & $\%$ & Herd & \\
\hline & Protein & $\%$ & Animal & \\
\hline & Lactose & & Herd & \\
\hline & Urea & $\mathrm{mg} / \mathrm{dL}$ & Herd & \\
\hline & FFA & $\mathrm{mmol} / 100 \mathrm{~g}$ & Herd & \\
\hline & Butyric acid bacteria & Yes/no & Herd & \\
\hline & Antibiotics $^{2}$ & Yes/no & Herd & \\
\hline & $\mathrm{SCC}$ & Cells/mL & Herd & \\
\hline & $\mathrm{SCC}$ & Cells/mL & Animal & \\
\hline \multirow[t]{2}{*}{ Reproduction } & & Date & Animal & \multirow{2}{*}{$\begin{array}{l}56 \text {-d nonreturn rate }(\%) \text {, average services per cow, cows with more than } 2 \\
\text { services }(\%) \text {, abortion }(\%) \text {, average expected calving interval (d), average } \\
\text { realized calving interval (d), average interval calving to first service (d) }\end{array}$} \\
\hline & Calving & Date & Animal & \\
\hline
\end{tabular}

${ }^{3}$ Economic returns per average kilogram of milk, fat, and protein, based on 305-d milk yield, fat contents, and protein contents, corrected for calving interval and age and season of calving.

${ }^{4}$ Udder infection is defined as SCC $>150,000$ cells $/ \mathrm{mL}$ in first-parity cows and SCC $>250,000$ cells/mL in second-or-higher-parity cows. 
milk SCC, new udder infections, and fluctuations in standardized milk production. A herd was assigned zero points per variable when it was among the $10 \%$ worst values and 10 points when it was among the $90 \%$ best values of all herds in the RHD database in 2004 . Subsequently, 500 herds were approached to participate in the study: 250 herds were randomly selected from the $5 \%$ lowest CHS (i.e., CHS $\leq 40$ ) and 250 herds from the $95 \%$ highest CHS (i.e., CHS >40). From these 500 herds, 163 farmers responded positively, 75 negatively, and 262 failed to respond. Nonresponders were contacted by phone. In total, 196 farmers agreed to participate: 90 from the 5\% lowest CHS and 106 from the $95 \%$ highest CHS.

\section{Data Collection and Processing}

Dairy Cattle Welfare. Seven observers, all with previous experience in dairy production and handling, were trained to use the Welfare Quality assessment protocol for dairy cattle (Welfare Quality, 2009) in a 3 - $d$ course given by delegates of the Welfare Quality consortium. Each observer visited 14 to 48 herds during the winter months of November 2009 through March 2010, when cows had been denied access to pasture for at least 2 wk. During a farm visit, observers collected data for 41 WI using assessment methods described briefly below [details can be found in Welfare Quality (2009)].

For the avoidance distance (AD) at the feeding rack, which was measured on a predefined sample of lactating and dry cows (Welfare Quality, 2009), the observer approached individual cows from the front, starting at a distance of $2 \mathrm{~m}$ at the feed bunk. The AD was estimated at the moment the cow moved back, turned, or pulled back the head, and was categorized in 1 of 4 categories: $>100 \mathrm{~cm}, 100$ to $>50 \mathrm{~cm}, 50$ to $>0 \mathrm{~cm}$, or touched. The percentage of cows in each AD category was weighted and aggregated into an $\mathrm{AD}$ index, ranging from 0 (worst) to 100 (best). For the qualitative behavior assessment (Wemelsfelder, 2007), cows were observed in segments of the barn for $20 \mathrm{~min}$, regardless of the number of cows in the herd or in a segment. After this observation, 20 descriptors were scored on a visual analog scale between 0 (expressive quality of the descriptor was entirely absent in any of the animals) and $125 \mathrm{~mm}$ (dominant across all observed animals). The 20 descriptors were weighted and aggregated into a qualitative behavior index, ranging from -10 (worst) to 7 (best). Subsequently, lying behavior, agonistic behavior, and coughing were recorded in segments (with a maximum of approximately 25 lactating cows) using continuous behavior sampling (Martin and Bateson, 1993). During clinical observations, 13 health indica- tors (Table 2) were assessed for a predefined sample of lactating and dry cows. Body condition was scored on a 5 -point scale and grouped into classes "very lean" (score 1 ) and "not very lean" (score $\geq 2$ ). Locomotion was scored on a 5-point scale and grouped into classes "not lame" (scores 1 and 2), "lame" (score 3), and "severely lame" (scores 4 and 5). Assessment details of other indicators of the clinical observations can be found in the Welfare Quality protocol (Welfare Quality, 2009). Besides this, 20 WI were collected using a resources checklist and an interview. Identical indicators were used for cattle in loose housing and tie-stalls, except for lameness. Cows in tie-stalls were categorized in 2 lameness classes (not lame or lame), instead of 3 (not lame, lame, or severely lame).

Data collected at the animal level was expressed as WI at the herd level (Table 2). Continuous WI were converted to a binary scale, representing a minor or severe problem based on threshold values for a "serious problem" or "alarm," described in Welfare Quality (2009; Table 2). When threshold values were not available in the Welfare Quality protocol, WI were dichotomized using the 75 th percentile as a threshold value.

$\boldsymbol{R H D}$. After all farm visits were done, RHD described in Table 1 were extracted from the RHD database. We expected that associations between RHD and WI would be the strongest when RHD were collected over a period of time long enough to average out day-to-day fluctuations, but short enough to reflect the influence of recent management practices or environmental changes on cattle productivity, health, and welfare. Therefore, RHD were extracted for the quarter of the year in which the on-farm welfare assessment was performed: October through December 2009, or January through March 2010. For some RHD, data were extracted for a longer period of time to ensure sufficient events (slaughter and on-farm mortality), to include changes over time (change in herd size and net result and new udder infections), to avoid seasonal variation (milk fat, protein, and urea), or to include reproduction parameters (e.g., calving interval). Missing values in the RHD database were replaced, if available, with the herd average of quarters of the year 2009. Besides data available in the RHD database, additional data (Table 1) were obtained during the farm visits that could potentially be used as RHD because they are easy to register. Raw data were expressed as 46 variables of RHD at the herd level (Table 1).

\section{Statistical Analyses}

To explore associations between continuous variables of RHD and WI, Spearman rank correlations were calculated. They were preferred over Pearson correlations, 
Table 2. Threshold values ${ }^{1}$ for conversion of continuous welfare indicators to a binary scale (minor or major problem) and observed prevalence per class for 194 selected Dutch dairy herds

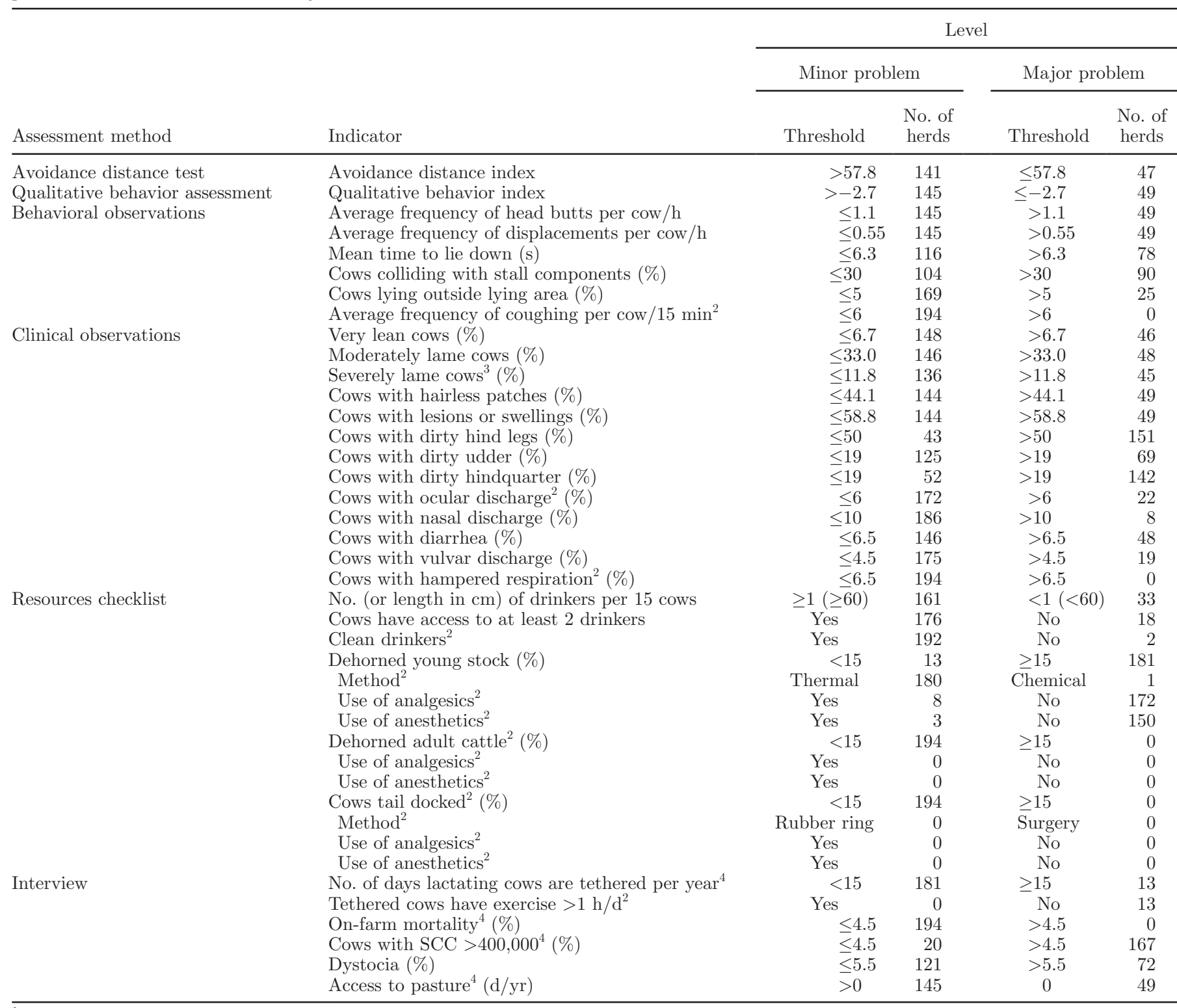

${ }^{1}$ Threshold values adapted from Welfare Quality (2009). If not available in Welfare Quality (2009), threshold value was based on the $25 \%$ worstscoring herds in this study.

${ }^{2}$ Indicator excluded from predictions due to observed prevalence $<5 \%$ for 1 of the 2 classes.

${ }^{3}$ Assessed in loose-housing systems only.

${ }^{4}$ Indicator excluded from predictions because it was in the list of routine herd data.

because several variables could not be assumed to be (approximately) normally distributed. Variables of RHD and WI were not included in the statistical analyses when the standard deviation was zero (for continuous variables) or the prevalence among classes less than $5 \%$ (for binary variables). Calculations for correlations and building of prediction models were performed with GenStat software (VSN International Ltd., 2011), and evaluation of the predictive ability of models with IBM SPSS Statistics 19.0 (SPSS Inc., 2010).

Building Prediction Models. Dichotomized WI were considered as response variables $(\mathrm{Y})$ and variables of RHD as predictors $(\mathrm{X})$ in logistic regression with herd as sampling unit. To judge their potential for prediction, each predictor was first screened individually by fitting a simple generalized linear model (McCullagh 
and Nelder, 1989) specifying a binomial distribution with a logit link function. Quadratic terms of some predictors were included in the analyses to capture potential nonlinear associations with the response variable (de Vries et al., 2011). Predictors with a $P$-value (from the Wald test) below 0.20 in the first screening were included in subsequent multivariate analyses. The number of predictors was further reduced in the multivariate analyses, using both backward and forward stepwise procedures, with the Akaike information criterion as a selection criterion. On the union of the 2 final models of the stepwise procedures, predictors were selected in best subset selection based on a minimum Akaike information criterion value. Only predictors with a $P$-value (from the Wald test) below 0.10 were retained in the final model. For each WI, the final model yielded a posterior probability (between 0 and 1 ) for each herd to be in the severe problem class. A cutoff value could be chosen in the next steps for this posterior probability to classify herds as having a minor (probability < cutoff value) or severe problem (probability $\geq$ cutoff value).

Evaluating Predictive Ability of the Models. The predictive ability of each model was evaluated based on Se and Sp for the observed and predicted classification of herds. Sensitivity was defined as the proportion of herds correctly predicted to have a severe problem. Specificity was similarly defined for herds in the minor problem class. A trade-off exists between Se and Sp; lowering the cutoff value for the posterior probability results in an increased Se and decreased Sp, whereas raising the cutoff value results in the opposite effect (Dohoo et al., 2009).

To evaluate the overall performance of each prediction model, Se and Sp were calculated for various cutoff values. Sensitivity and 1 - Sp (i.e., proportion of false positives) were plotted in a receiver operating curve (ROC) and the area under the ROC curve (AUC) was calculated. The AUC is a summary statistic of diagnostic accuracy, equivalent to the probability that the model will rank a randomly chosen herd with a severe problem higher than a randomly chosen herd with a minor problem (Greiner et al., 2000). The AUC values were interpreted using an informal classification system for accuracy of prediction as suggested by Greiner et al. (2000): noninformative (AUC $=0.5)$, less accurate $(0.5<$ AUC $\leq 0.7)$, moderately accurate $(0.7<$ AUC $\leq 0.9)$, highly accurate $(0.9<\mathrm{AUC}<1.0)$, and perfect $(\mathrm{AUC}=1)$. The AUC values of each prediction model are shown in the results. As an example, final prediction models and ROC curves are shown for the WI with the highest AUC, for the animal-based WI with the highest AUC, and for the percentage of severely lame cows. Lameness was chosen because it has been recognized as the most important issue regarding dairy cattle welfare (Whay et al., 2003; Lievaart and Noordhuizen, 2011).

Subsequently, the performance of prediction models was evaluated for 3 levels of Se and Sp: high Se, high Sp, and both sizeable Se and Sp. To evaluate the performance of prediction models with a high Se level, the cutoff value for the posterior probability was set such that Se was at least $97.5 \%$. Specificity was determined for this cutoff value $\left(\mathbf{S p}_{\mathrm{Se}}=\mathbf{9 7 . 5 \%}\right)$. To evaluate the performance of prediction models with a high Sp level, the cutoff value for the posterior probability was set such that $\mathrm{Sp}$ was at least $97.5 \%$ (i.e., $2.5 \%$ false positives). Sensitivity was determined for this cutoff value $\left(\mathbf{S e}_{\mathbf{S p}}=\right.$ 97.5\%). To optimize the proportion of correctly classified herds in both the minor and severe problem class, the cutoff value for the posterior probability was set such that the sum of Se and Sp was maximized $\left[\mathbf{S}_{\max }=\max \right.$ $(\mathrm{Se}+\mathrm{Sp})]$. Sensitivity, Sp, and the percentage of correctly classified herds (i.e., accuracy) were determined for this cutoff value $\left(\mathbf{S e}_{\mathbf{S m a x}}, \mathbf{S p}_{\mathbf{S m a x}}\right.$, and $\left.\mathbf{A} \mathbf{C C}_{\mathbf{S m a x}}\right)$.

\section{RESULTS}

Animal welfare and routine herd data were collected from 196 Dutch dairy herds, yielding data for 41 WI and 46 variables of RHD. Data of 2 herds was excluded from the analyses because the Welfare Quality protocol could not be executed correctly in these herds. In the remaining 194 herds, herd size ranged from 10 to 211 lactating cows and average milk production from 9.7 to $34.5 \mathrm{~kg}$ per cow/d. Cows were loose housed on 181 farms and tied on 13 farms. On 153 farms, cows had access to pasture in summer and 42 herds had an automatic milking system. Twelve herds showed missing values of RHD. In 1 of these herds, missing values were replaced by historical data of the year 2009. In the remaining 11 herds, in which missing values were either partly (3 herds) or not ( 8 herds) replaced by historical data, the number of missing values ranged from 1 to 20 variables of RHD per herd. Nineteen WI were excluded from the statistical analyses because they showed a prevalence of less than $5 \%(15 \mathrm{WI})$, or were already listed as variables of RHD (4 WI; Table 2).

For the 194 selected study herds, correlations between continuous WI and variables of RHD ranged from -0.33 (average milk production per cow per day versus percentage of cows with dirty hindquarters) to 0.31 (average SCC of cows 120 to 210 DIM versus percentage of moderately lame cows). For dichotomized WI, the number of severe problems ranged from 3 to 17 per herd. Out of the 46 variables of RHD that were considered, 36 were included in final prediction models of 1 or more WI (Appendix Table A1). Variables of RHD 
relating to identification and registration were included in the largest number of prediction models, followed by variables relating to milk composition, management, milk production, and fertility. The variable of RHD most frequently included in final models was on-farm mortality of cows less than 60 DIM (included in models of $8 \mathrm{WI})$.

\section{Overall Performance of Prediction Models}

Median AUC was 0.73, ranging from 0.57 (AD index) to 0.96 (access to at least 2 drinkers; Table 3). Except for the AD index, AUC was significantly higher than 0.5 for all WI. The AUC values were interpreted as a less accurate prediction for $7 \mathrm{WI}$, a moderately accurate prediction for $14 \mathrm{WI}$, and a highly accurate prediction for 1 WI (resource based). When only AUC of animal-based WI were compared, AUC ranged from 0.57 (AD index) to 0.81 [percentage of cows lying (partly) outside the supposed lying area, percentage of very lean cows, and percentage of cows with vulvar discharge], which was interpreted as a less to moderately accurate prediction.

Figure 1 shows ROC curves for the WI with the highest AUC (access to at least 2 drinkers), for the animal-based WI with the highest AUC and smallest $95 \%$ confidence interval (percentage of very lean cows), and for the percentage of severely lame cows. Access to less than 2 drinkers was associated with a smaller herd size and a lower replacement rate (Table 4). The risk of more than $6.7 \%$ very lean cows was associated with a higher replacement rate, higher on-farm mortality, and higher SCC of cows less than 60 DIM, no on-farm mortality of cows 120 to 210 DIM, more services per cow, shorter expected calving interval, and was nonlinearly associated with milk fat contents and the interval from calving to first service (Table 5). The risk of more than $12 \%$ severely lame cows was associated with zerograzing, a larger herd size, higher on-farm mortality of cows 0 to 60 DIM, on-farm mortality of cows 120 to 210 DIM, a higher proportion of fat:protein in cows less than 60 DIM, and was nonlinearly associated with average DIM (Table 6).

\section{Performance of Models for Different Levels of Se and Sp}

By forcing almost all herds with a severe problem to be detected (i.e., an Se of 97.5\%), median

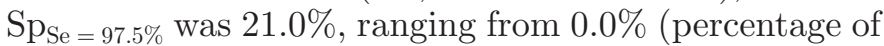
cows colliding with components of the stall) to $80.7 \%$ (access to at least 2 drinkers; Table 3 ). This indicates that 19.3 to $100 \%$ of the herds were incorrectly assumed to have a severe problem (i.e., false positives). When only $\mathrm{Sp}_{\mathrm{Se}=97.5 \%}$ of animal-based WI were compared, the highest $\mathrm{Sp}_{\mathrm{Se}}=97.5 \%$ was $39.3 \%$ (percentage of very lean cows).

Table 3. Performance [area under the curve (AUC) and $95 \% \mathrm{CI}$ ], sensitivity (Se) given a specificity (Sp) of $97.5 \%\left(\mathrm{Se} \mathrm{Sp}_{\mathrm{p}}=97.5 \%\right)$, Sp given an Se of $97.5 \%\left(\mathrm{Sp}_{\mathrm{Se}}=97.5 \%\right)$, and $\mathrm{Se}, \mathrm{Sp}$, and accuracy $(\mathrm{ACC})$ given a maximized sum $(\mathrm{S})$ of Se and $\mathrm{Sp}\left(\mathrm{Se} \mathrm{Smax}_{\mathrm{x}}, \mathrm{Sp}_{\mathrm{Smax}}\right.$, and $\mathrm{ACC}_{\mathrm{Smax}}$, respectively) of prediction models for welfare indicators

\begin{tabular}{|c|c|c|c|c|c|c|}
\hline Indicator & $\begin{array}{c}\text { AUC } \\
(95 \% \text { CI })\end{array}$ & $\begin{array}{c}\mathrm{Se}_{\mathrm{Sp}}=97.5 \% \\
(\%)\end{array}$ & $\begin{array}{c}\mathrm{Sp}_{\mathrm{Se}}=97.5 \% \\
(\%)\end{array}$ & $\begin{array}{c}\mathrm{Se}_{\text {Smax }} \\
(\%)\end{array}$ & $\begin{array}{c}\mathrm{Sp}_{\operatorname{smax}} \\
(\%)\end{array}$ & $\begin{array}{c}\mathrm{ACC}_{\mathrm{Smax}} \\
(\%)\end{array}$ \\
\hline Avoidance distance index & $0.57(0.48-0.67)^{1}$ & 6.4 & 5.1 & 53.2 & 63.0 & 60.6 \\
\hline Qualitative behavior index & $0.73(0.64-0.82)$ & 33.3 & 9.8 & 47.9 & 91.6 & 80.6 \\
\hline Average frequency of displacements & $0.70(0.62-0.78)$ & 14.6 & 14.0 & 81.3 & 58.7 & 64.4 \\
\hline Mean time to lie down $(\mathrm{s})$ & $0.77(0.70-0.84)$ & 13.2 & 7.9 & 51.3 & 90.4 & 74.7 \\
\hline Cows colliding with stall components (\%) & $0.64(0.56-0.72)$ & 3.4 & 0.0 & 40.2 & 83.3 & 63.3 \\
\hline Moderately lame cows (\%) & $0.77(0.68-0.85)$ & 14.3 & 21.7 & 66.7 & 85.3 & 80.7 \\
\hline Severely lame cows ${ }^{2}(\%)$ & $0.75(0.67-0.83)$ & 20.5 & 23.5 & 70.5 & 72.0 & 71.6 \\
\hline Cows with hairless patches (\%) & $0.64(0.55-0.72)$ & 4.1 & 23.6 & 89.8 & 38.2 & 51.3 \\
\hline Cows with lesions or swellings (\%) & $0.73(0.65-0.82)$ & 19.1 & 14.1 & 55.3 & 82.4 & 75.5 \\
\hline Cows with dirty hind legs (\%) & $0.69(0.60-0.78)$ & 9.0 & 22.0 & 75.7 & 53.7 & 70.8 \\
\hline Cows with dirty udder $(\%)$ & $0.75(0.68-0.82)$ & 16.2 & 9.8 & 77.9 & 64.8 & 69.5 \\
\hline Cows with dirty hindquarters (\%) & $0.72(0.65-0.80)$ & 29.6 & 6.0 & 60.0 & 78.0 & 64.8 \\
\hline Dehorning young stock (\%) & $0.84(0.72-0.96)$ & 23.5 & 30.8 & 83.8 & 76.9 & 83.3 \\
\hline Dystocia (\%) & $0.60(0.52-0.68)$ & 0.0 & 5.8 & 59.7 & 59.5 & 59.6 \\
\hline
\end{tabular}

${ }^{1}$ Area under the curve not significantly $(P>0.05)$ higher than 0.5 .

${ }^{2}$ Assessed in loose-housing systems only. 
Table 4. Results from a logistic regression of access to at least 2 drinkers on routine herd data (193 herds; mean deviance $=31.9 ; P$ $<0.001)$

\begin{tabular}{lcr}
\hline Predictor & $\begin{array}{c}\text { Estimate } \\
(\mathrm{SE})\end{array}$ & $P$-value \\
\hline Constant & $6.6(2.0)$ & \\
Herd size & $-0.12(0.03)$ & $<0.001$ \\
Replacement $(\%)$ & $-0.08(0.05)$ & 0.098 \\
\hline
\end{tabular}

By forcing almost no herds to be incorrectly classified as having a severe problem (i.e., an Sp of 97.5\%), median $\mathrm{Se}_{\mathrm{Sp}=97.5 \%}$ was $15.4 \%$, ranging from $0.0 \%$ [number (length) of drinkers and percentage of dystocia] to $66.7 \%$ (access to at least 2 drinkers; Table 3). When only $\mathrm{Se}_{\mathrm{Sp}=97.5 \%}$ of animal-based WI were compared, the highest $\mathrm{Se}_{\mathrm{Sp}}=97.5 \%$ was $36.8 \%$ (percentage of cows with vulvar discharge).

By optimizing the proportion of correctly classified herds in the minor and severe problem class (i.e., a maximum sum of Se and Sp), median $\mathrm{Se}_{\mathrm{Smax}_{\max }}$ was $69.1 \%$ and median $\mathrm{Sp}_{\text {Smax }}$ was $71.2 \%$. Similar to AUC, the maximized sum of Se and Sp was lowest for the $\mathrm{AD}$ index $\left(\mathrm{Se}_{\mathrm{Smax}}=53.2\right.$ and $\mathrm{Sp}_{\mathrm{Smax}}=63.0$; Table 3) and highest for access to at least 2 drinkers $\left(\mathrm{Se}_{\mathrm{Smax}}=100\right.$ and $\left.\mathrm{Sp}_{\mathrm{Smax}}=80.7\right)$. When only animal-based indicators were considered, the maximized sum of Se and Sp was highest for percentage of moderately lame cows $\left(\mathrm{Se}_{\mathrm{Smax}}\right.$ $=66.7$ and $\mathrm{Sp}_{\mathrm{Smax}}=85.3$ ). The median percentage of correctly classified herds was $69.7 \%$, ranging from $51.3 \%$ (percentage of cows with hairless patches) to $88.1 \%$ (percentage of cows with vulvar discharge; Table 3).

\section{DISCUSSION}

Our aim was to explore the value of RHD for estimating dairy cattle welfare at the herd level, by using different levels of Se and Sp. To this end, the predictive potential of 46 variables of RHD was evaluated for each

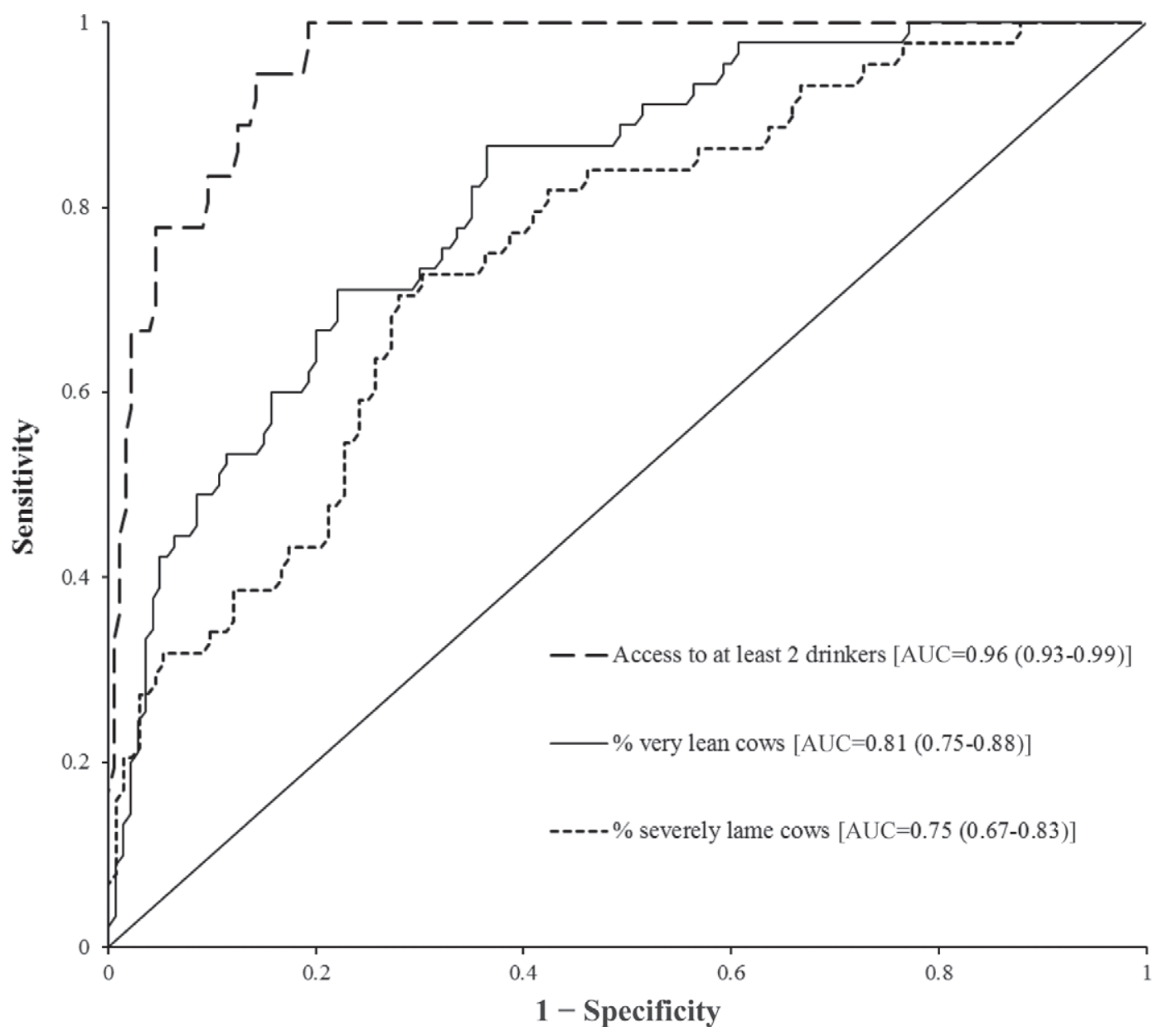

Figure 1. Receiver operating curves representing the predictive ability of the models for 3 welfare indicators: access to at least 2 drinkers, percentage of very lean cows, and percentage of severely lame cows. AUC = area under the receiver operating curve (95\% CI); the diagonal line represents an AUC of 0.5 . 
Table 5. Results from a logistic regression of percentage of very lean cows on routine herd data (184 herds; mean deviance $=4.5 ; P<0.001)$

\begin{tabular}{lcc}
\hline & Estimate & \\
Predictor & $(\mathrm{SE})$ & $P$-value \\
\hline Constant & $-127.3(59.2)$ & \\
Replacement (\%) & $0.07(0.03)$ & 0.018 \\
On-farm mortality of cows 0 to 60 DIM (\%) & $0.21(0.11)$ & 0.047 \\
On-farm mortality of cows 120 to 210 DIM (yes/no) & $-1.4(0.52)$ & 0.009 \\
Milk fat (\%) & $65.5(32.0)$ & 0.040 \\
Milk fat (\%) squared & $-9.2(4.4)$ & 0.037 \\
Average SCC of cows 0 to 60 DIM (10 ${ }^{3}$ cells $\left./ \mathrm{mL}\right)$ & $0.003(0.001)$ & 0.023 \\
Average services per cow & $4.1(1.4)$ & 0.003 \\
Average expected calving interval & $-0.05(0.02)$ & 0.028 \\
Interval from calving to first service (d) & $0.3(0.13)$ & 0.017 \\
Interval from calving to first service (d) squared & $-0.001(0.0006)$ & 0.059 \\
\hline
\end{tabular}

of the 41 WI of the Welfare Quality protocol for dairy cattle. Four of these WI were already listed as RHD: the percentage of on-farm mortality, the percentage of cows with an SCC $>400,000$, access to pasture, and tethering of cows. These WI can, therefore, be assessed without needing to verify the values in an on-farm welfare assessment. Fifteen other WI showed a prevalence of less than $5 \%$. With the exception of $5 \mathrm{WI}$ relating to issues that are regulated by law in many countries (tail docking and use of anesthetics for dehorning young stock), we do not recommend exclusion of these indictors from the Welfare Quality protocol because herds in our study may not be representative of other populations and prevalence can change over time.

Herds in this study were selected on the basis of a CHS to achieve more variation in the level of animal welfare. Whereas associations between the variables in this CHS and WI had been reported mainly at the animal level or in experimental settings so far (de Vries et al., 2011), CHS appeared useful in selecting for variation in welfare of commercial dairy herds in the current study. Herds selected from the $5 \%$ lowest CHS were more often housed in tie-stalls; showed more cows with dirty hindquarters, more cows with high SCC, and fewer cows with diarrhea; had a higher on-farm mortality and fewer calves disbudded, and scored lower for 8 descriptors of the Qualitative Behavior Assessment than herds selected from the $95 \%$ highest CHS $[P<$ 0.05; results presented in de Vries et al. (2013)].

Three methodological aspects of the current study restrict interpretation of the results. First, the choice of parameters in the CHS may have resulted in selecting a specific group of herds with poor welfare, whereas other herds with poor welfare were overlooked. We expect, however, that the influence of the choice of parameters on selection of predictors in our regression models was limited, because our sample of herds was heterogeneous in many respects. Herd size, for example, ranged from 10 to 211 cows, milk production ranged from 9.7 to $34.5 \mathrm{~kg}$ per cow $/ \mathrm{d}$, cows were pastured in three-fourths of the herds, and an automated milking system was present in one-fourth of the herds. Besides this, the fact that variables in the CHS were also used for prediction of WI most likely resulted in stronger correlations between observed and predicted WI values. This may have slightly inflated estimated Se and Sp, because herds with more extreme values are easier to detect for predictors. However, the evaluation of the multiple regression models can be expected to be markedly more accurate for selected herds than for random herds, which was the prevailing argument for selection of herds.

Second, because our aim was to evaluate the potential of RHD for prediction of WI, causalities of associa-

Table 6. Results from a logistic regression of percentage of severely lame cows on routine herd data (175 herds; mean deviance $=3.6 ; P<0.001)$

\begin{tabular}{lcc}
\hline & $\begin{array}{c}\text { Estimate } \\
(\mathrm{SE})\end{array}$ & $P$-value \\
\hline Predictor & $-24.1(8.7)$ & \\
Constant & $-0.79(0.46)$ & 0.087 \\
Access to pasture & $0.009(0.005)$ & 0.074 \\
Herd size & $0.05(0.03)$ & 0.065 \\
Mortality of cows <60 DIM (\%) & $0.50(0.24)$ & 0.035 \\
Mortality of cows 120 to 210 DIM (\%) & $0.16(0.08)$ & 0.057 \\
Average DIM (d) & $-0.0004(0.0002)$ & 0.074 \\
Average DIM, squared term & $4.8(2.3)$ & 0.039 \\
Proportion of fat to protein of cows <60 DIM & & \\
\hline
\end{tabular}


tions between RHD and WI were not considered, and regression models were not checked for confounding. Therefore, it has to be emphasized that associations found in this study do not necessarily imply a direct causal relationship between RHD and WI. Despite the fact that a causal relationship might not exist, some of the predictors included in the final models for prediction of WI were possibly indicative of management styles related to welfare in herds [e.g., the certification for a bovine viral diarrhea (BVD)-, infectious bovine rhinotracheitis (IBR)-, or Salmonella-free status]. For some other predictors, an association with the outcome variable was not expected. A result contradictory to our expectation, for example, was an association between a reduction in herd size and a severe problem for the percentage of cows lying (partly) outside the supposed lying area. Including variables in the prediction model where a causal relationship is doubtful might make future predictions less accurate (Dohoo et al., 2009). As in any study where prediction variables are selected and the number to select from is relatively large, an element of overfitting and chance relationships is involved. Because methodological aspects of the current study may have influenced the selection of prediction variables, promising prediction models should be validated in additional field studies before they can be applied in practice. Sensitivity and Sp of models should be regularly reevaluated in additional field studies hereafter, because indirect relationships between predictors and WI may change.

Third, data quality of WI and RHD may have influenced performance of prediction models. We did not evaluate reliability of WI (the extent to which the same results are obtained among and within observers; Knierim and Winckler, 2009) in the current study, because the objective of Welfare Quality was to develop a protocol built on evidence-based indicators. This does not necessarily imply, however, that reliability of all indicators is high. Bokkers et al. (2012), for example, found low interobserver reliability for the Qualitative Behavior Assessment. Similarly, RHD can be subject to change, falseness, or incompleteness, in spite of standardized methods of collecting RHD that create the expectation of a certain reliability level (ICAR, 2012). Not only may reliability of WI and RHD have influenced performance of prediction models in the current study, sufficient reliability of RHD should also be guaranteed if welfare predictions are used for certification purposes.

\section{Performance of Final Models}

Despite modest correlations between individual variables of RHD and WI, predictions of WI were less to highly accurate. This suggests that RHD have value for estimating almost all WI in the Welfare Quality protocol for dairy cattle. The prediction model for the index for $\mathrm{AD}$ of cows at the feeding rack did not do better than a random guess. This does not imply that this WI is not a valid indicator for animal welfare, but it shows that little association existed with variables of RHD included in this study. Associations between RHD and this WI were also absent in earlier studies (Waiblinger et al., 2002; Waiblinger et al., 2003). For other types of human-animal relationship tests, however, associations have been found. Flinch, kick, and step responses during milking, for example, were negatively associated with milk yield and protein contents, whereas the percentage of cows approaching close to a human was positively associated with milk yield and conception rate at first service (Breuer et al., 2000; Hemsworth et al., 2000; Bertenshaw et al., 2008). Also, aversive handling by stock people was negatively associated with milk yield, and protein and fat contents of milk in various studies (Rushen et al., 1999; Breuer et al., 2000; Hemsworth et al., 2000; Hemsworth et al., 2002). Hence, RHD might be more relevant for indicators showing the humananimal relationship other than the $\mathrm{AD}$ at the feeding rack.

The best performing prediction model was the model for access to at least 2 drinkers, which is a resourcebased indicator. This WI was strongly associated with herd size; farms in which cows had access to at least 2 drinkers housed 91 cows, on average, whereas farms in which cows had access to less than 2 drinkers housed 36 cows. Housing system was probably a confounding factor for this association. Thirteen of the 18 herds with access to less than 2 drinkers were housed in tie-stalls, and providing more than 1 drinker per cow is not common for tie-stalls in the Netherlands.

When only animal-based WI were considered, the best-performing models were those of the percentage of cows lying (partly) outside the supposed lying area, percentage of very lean cows, and percentage of cows with vulvar discharge. To our knowledge, no other studies have investigated associations between variables of RHD and cows lying outside the supposed lying area, except for 1 study that indicated an association with housing system (Plesch et al., 2010). The association between a severe problem for the percentage of very lean cows and a higher replacement rate was comparable with results of Hoedemaker et al. (2009) and Machado et al. (2010), who found that cows with a lower BCS were more likely to be culled and had a shorter survival time than cows with higher BCS. Similar to our results, other studies showed an association of very lean cows with lower milk fat contents (Berry et al., 2007a; Roche et al., 2007a), higher SCC (Berry et al., 2007b; Breen et al., 2009), and worse reproductive performance (e.g., 
Buckley et al., 2003; Roche et al., 2007b). Associations between vulvar discharge and calf mortality or pregnancy rate (Peeler et al., 1994; Gautam et al., 2010) were not found in our study. To our knowledge, associations between vulvar discharge and age, mortality, urea contents of milk, and certified disease-free statuses in our study have not been investigated in other studies so far.

Predictions of WI measured in behavioral observations were only slightly less accurate than predictions of WI measured in clinical observations (median AUC $=0.70$ vs. 0.75 ). So far, few other studies have investigated associations between behavioral WI and variables of RHD (de Vries et al., 2011). Similar to the results of our study, agonistic interactions (i.e., head butts and displacements) have been associated with average age (Mülleder et al., 2007). Agonistic interactions increase when new animals (which are often heifers) are introduced into established social groups (von Keyserlingk et al., 2008). Also, a higher dominance rank of individual cows based on their agonistic interactions has been associated with higher age, and with higher fat contents of milk (Andersson et al., 1984; Val-Laillet et al., 2008), but these are not necessarily comparable with the herdlevel associations between agonistic interactions, average age, and average fat contents in our study.

Overall performance of our prediction models could not be compared with results of similar studies by Sandgren et al. (2009) and Nyman et al. (2011), because they did not report AUC values. These studies reported a correct classification of 77 and $76 \%$ of the herds, with an Se of 77 and $96 \%$, and an Sp of 91 and $56 \%$, respectively. In both studies, prediction models were developed with the aim to enhance both Se and Sp, which might be more or less comparable with our method of maximizing the sum of Se and Sp. Considering the same animal-based indicators as included by Sandgren et al. (2009) and Nyman et al.(2011) only, the median performance of our prediction models seemed not as good as the performance of the models of Sandgren et al. (2009) and Nyman et al. (2011); slightly fewer herds in our study were classified correctly $\left(\mathrm{ACC}_{\operatorname{Smax}}=71 \%\right)$, with a lower Se $\left(\mathrm{Se}_{\mathrm{Smax}}=\right.$ $71 \%)$ and an intermediate $\mathrm{Sp}\left(\mathrm{Sp}_{\mathrm{Smax}}=72 \%\right)$. Reasons for this difference might be related to the use of a different outcome variable (WI were analyzed separately in our study, and concerned adult dairy cows only), different variables of RHD, and a different procedure for selection of prediction variables. Besides this, results of Sandgren et al. (2009) and Nyman et al. (2011) were based on a smaller number of herds and a greater number of RHD to select from, which might have induced (more) overfitting and, consequently, a more optimistic impression of the predictive power.

\section{Predictors of Dairy Cattle Welfare}

Prediction variables most frequently included in final models were RHD relating to identification and registration (18 WI), especially on-farm mortality in different lactation stages (15 WI). This is consistent with results of Sandgren et al. (2009) and Nyman et al. (2011), who considered 9 animal-based indicators: cleanliness, body condition (assessed in calves, young stock, and dairy cows), injuries and inflammations, lameness, and rising behavior (assessed in dairy cows only). Besides mortality rates, Sandgren et al. (2009) and Nyman et al. (2011) included fertility measures, stillbirth rate, mastitis incidence, and incidence of feed-related diseases as predictors in their final models. In our study, RHD relating to fertility and stillbirth were predictors for similar WI: the percentage of cows with dirty hind legs, dirty hindquarters, and diarrhea; very lean cows, moderately lame cows, and cows lying (partly) outside the supposed lying area. Mastitis incidence and incidence of feed-related diseases are not routinely collected in the Netherlands.

Type of housing was initially included in models of 5 WI, but excluded from the final model because the $P$-value exceeded 0.10 . The lack of significance was probably due to the small number of tie-stalls in our study. On the other hand, contrary to our hypothesis that relations between WI and RHD do not necessarily depend on the type of housing system, the lack of significance might as well indicate that associations between variables of RHD and WI are different for these 2 types of housing systems. Therefore, more data are needed to evaluate associations between variables of RHD and WI in tie-stalls separately.

\section{Value of RHD for Practical Applications}

The value of RHD for estimating WI was evaluated for different levels of Se and Sp (high Se, high Sp, and highest sum of Se and Sp) to judge its suitability for different applications. First, an Se of $97.5 \%$ was set to force that almost all herds with a severe welfare problem were detected. An example of an application is the use of RHD as a prescreening tool in which the welfare level of herds is first estimated based on RHD. Due to its trade-off with $\mathrm{Sp}$, setting Se to $97.5 \%$ resulted in an Sp below $40 \%$ for most WI. This means that more than half of the herds were incorrectly assumed to have a severe problem. Using RHD as a prescreening tool for detecting almost all herds with a severe welfare problem, therefore, demands verification of the level of welfare in an on-farm assessment to identify false positives. In terms of a reduction in time (and costs), this tool shows a large advantage compared with random 
farm visits for identification of herds with a severe welfare problem. Assuming a population of 18,000 dairy herds (which is the approximate number of dairy herds in the Netherlands) in which $25 \%$ of the herds have a severe problem for the percentage of cows with severe lameness, for example, application of this prescreening tool would result in a reduction of $16 \%$ of the number of farms that need to be visited to detect at least $97.5 \%$ of the herds with a severe problem, compared with random farm visits. Time reduction can be improved even more if the proportion of herds with a severe problem that needs to be detected is lower. For example, to detect $70 \%$ of the herds with a severe problem for the same population, application of the prescreening tool would result in a reduction of $45 \%$ of the number of farm visits, compared with random farm visits.

Next, an Sp of $97.5 \%$ was set to force that almost none of the herds was incorrectly assumed to have a severe problem (i.e., few false positives). An example of an application is the use of RHD as an instant assessment tool for the level of dairy cattle welfare of herds in which the predicted welfare status is not verified in an on-farm assessment (due to, for example, costs being a serious impediment). Because the predicted status is not verified, an incorrect assumption of herds having a severe problem is not acceptable. Because of a tradeoff between Se and Sp, however, Se was below $40 \%$ for most WI and below $15 \%$ for half of the WI when Sp was set to $97.5 \%$. This means that, by keeping the number of false positives at a minimum, only a small part of the herds with a severe welfare problem will be detected. Except for WI that are already listed as RHD (on-farm mortality, SCC >400,000, access to pasture, and tethering), applying RHD as an assessment tool might lead to detection of only a very small proportion of the herds with a severe welfare problem, whereas many other herds with a severe problem are overlooked.

In the last step, the sum of Se and Sp was maximized to optimize the proportion of correctly classified herds in both the minor and severe problem class. An example of an application is the use of RHD as a monitoring tool to estimate the level of welfare in a population for which the prevalence is unknown, or to monitor levels of animal welfare over time. Results showed that, based on RHD, up to $81 \%$ herds could be classified correctly for the minor- and $100 \%$ for the severe-problem class of a resource-based indicator, and up to 85 and $67 \%$ for an animal-based indictor. This shows that RHD have value for estimating levels of dairy cattle welfare, but does not inform us how accurate levels of welfare would be estimated in a population for which the prevalence is unknown. Therefore, the use of RHD as a monitoring tool should be evaluated in additional field studies.

\section{Suggestions for Improvement}

Whereas prediction models were developed for individual WI in the current study, practical applications proposed above require that the various indicators are considered simultaneously. To decide whether a herd should be visited following a prescreening, for example, requires distinguishing between good and poor for an overall level of dairy cattle welfare. Aggregation of WI into an overall assessment of animal welfare, however, to some extent may be considered arbitrary (e.g., Fraser, 1995), because value judgments are inherently involved in the activity of attributing relative importance to welfare indicators and defining thresholds for good or poor welfare. In spite of different viewpoints, a method based on expert opinion has been developed specifically for aggregating Welfare Quality indicators, assigning herds to an unacceptable, acceptable, enhanced, or excellent class (Botreau et al., 2009). This enhances the opportunity to evaluate the potential of RHD for estimating an overall score for dairy cattle welfare at the herd level. This Welfare Quality classification method, however, needs further validation (de Vries et al., 2013).

Routine herd data were extracted from the RHD database for the quarter of the year in which the onfarm welfare assessment was performed and converted to variables of RHD at the herd level, based on average herd values. However, depending on the consistency of WI over time, variables of RHD might show a stronger correlation with WI when they cover a longer period of time. In addition, because many associations between variables of RHD and WI have been found at the individual cow level (de Vries et al., 2011), coefficients of variation might show potential to increase the value of RHD for estimating dairy cattle welfare. Besides this, additional data that can be easily obtained might contribute to more accurate predictions, such as results of postmortem inspections at abattoirs (e.g., Herva et al., 2011). The potential of these data for predicting WI at the herd level should be further investigated.

\section{CONCLUSIONS}

Routinely collected herd data have value for estimating dairy cattle welfare. For most welfare indicators, RHD can serve as a prescreening tool for the detection of herds with a severe welfare problem and, consequently, reduce the number of farm visits that are needed for routine assessment of animal welfare. The RHD also hold value for continuous monitoring of animal welfare, but are not very suitable for instant assessment of dairy cattle welfare. The true value of RHD for estimating dairy cattle welfare, however, should be validated in 
additional field studies. Besides this, the potential of RHD to estimate an overall welfare score for herds and additional data that can be easily obtained should be investigated to increase the value of RHD for estimating dairy cattle welfare.

\section{ACKNOWLEDGMENTS}

The authors gratefully acknowledge farmers for participating in this study, observers for their commitment to collecting the welfare data, and Henriette BrouwerMiddelesch (GD Animal Health Service, Deventer, the Netherlands) for her help with organizing the RHD.

\section{REFERENCES}

Andersson, M., J. Schaar, and H. Wiktorsson. 1984. Effects of drinking water flow rates and social rank on performance and drinking behaviour of tied-up dairy cows. Livest. Prod. Sci. 11:599-610.

Bareille, N., F. Beaudeau, S. Billon, A. Robert, and P. Faverdin. 2003. Effects of health disorders on feed intake and milk production in dairy cows. Livest. Prod. Sci. 83:53-62.

Berry, D. P., F. Buckley, and P. Dillon. 2007a. Body condition score and live-weight effects on milk production in Irish Holstein-Friesian dairy cows. Animal 1:1351-1359.

Berry, D. P., J. M. Lee, K. A. Macdonald, K. Stafford, L. Matthews, and J. R. Roche. 2007b. Associations among body condition score, body weight, somatic cell count, and clinical mastitis in seasonally calving dairy cattle. J. Dairy Sci. 90:637-648.

Bertenshaw, C., P. Rowlinson, H. Edge, S. Douglas, and R. Shiel. 2008. The effect of different degrees of 'positive' human-animal interaction during rearing on the welfare and subsequent production of commercial dairy heifers. Appl. Anim. Behav. Sci. 114:65-75.

Bicalho, R. C., L. D. Warnick, and C. L. Guard. 2008. Strategies to analyze milk losses caused by diseases with potential incidence throughout the lactation: A lameness example. J. Dairy Sci. 91:2653-2661.

Blokhuis, H. J., I. Veissier, M. Miele, and B. Jones. 2010. The Welfare Quality ${ }^{\circledR}$ project and beyond: Safeguarding farm animal well-being. Acta Agric. Scand. A Anim. Sci. 60:129-140.

Bokkers, E. A. M., M. de Vries, I. C. M. A. Antonissen, and I. J. M. de Boer. 2012. Inter- and intra-observer reliability of experienced and inexperienced observers for the Qualitative Behaviour Assessment in dairy cattle. Anim. Welf. 21:307-318.

Botreau, R., I. Veissier, and P. Perny. 2009. Overall assessment of animal welfare: Strategy adopted in Welfare Quality. Anim. Welf. 18:363-370.

Breen, J. E., A. J. Bradley, and M. J. Green. 2009. Quarter and cow risk factors associated with a somatic cell count greater than 199,000 cells per milliliter in United Kingdom dairy cows. J. Dairy Sci. 92:3106-3115.

Breuer, K., P. H. Hemsworth, J. L. Barnett, L. R. Matthews, and G. J. Coleman. 2000. Behavioural response to humans and the productivity of commercial dairy cows. Appl. Anim. Behav. Sci. 66:273-288.

Buckley, F., K. O'Sullivan, J. F. Mee, R. D. Evans, and P. Dillon. 2003. Relationships among milk yield, body condition, cow weight, and reproduction in spring-calved Holstein-Friesians. J. Dairy Sci. 86:2308-2319.

de Vries, M., E. A. M. Bokkers, T. Dijkstra, G. van Schaik, and I. J. M. de Boer. 2011. Invited review: Associations between variables of routine herd data and dairy cattle welfare indicators. J. Dairy Sci. 94:3213-3228.

de Vries, M., E. A. M. Bokkers, G. van Schaik, R. Botreau, B. Engel, T. Dijkstra, and I. J. M. de Boer. 2013. Evaluating results of the
Welfare Quality multi-criteria evaluation model for classification of dairy cattle welfare at the herd level. J. Dairy Sci. 96:6264-6273.

Dohoo, I. R., S. W. Martin, and H. Stryhn. 2009. Veterinary Epidemiologic Research. 2nd ed. VER Inc., Charlottetown, PE, Canada.

Fraser, D. 1995. Science, values and animal welfare: Exploring the 'inextricable connection'. Anim. Welf. 4:103-117.

Gautam, G., T. Nakao, K. Koike, S. T. Long, M. Yusuf, R. M. S. B. K. Ranasinghe, and A. Hayashi. 2010. Spontaneous recovery or persistence of postpartum endometritis and risk factors for its persistence in Holstein cows. Theriogenology 73:168-179.

Greiner, M., D. Pfeiffer, and R. D. Smith. 2000. Principles and practical application of the receiver-operating characteristic analysis for diagnostic tests. Prev. Vet. Med. 45:23-41.

Haskell, M. J., L. J. Rennie, V. A. Bowell, M. J. Bell, and A. B. Lawrence. 2006. Housing system, milk production, and zero-grazing effects on lameness and leg injury in dairy cows. J. Dairy Sci. 89:4259-4266.

Hemsworth, P. H., G. J. Coleman, J. L. Barnett, and S. Borg. 2000. Relationships between human-animal interactions and productivity of commercial dairy cows. J. Anim. Sci. 78:2821-2831.

Hemsworth, P. H., G. J. Coleman, J. L. Barnett, S. Borg, and S. Dowling. 2002. The effects of cognitive behavioral intervention on the attitude and behavior of stockpersons and the behavior and productivity of commercial dairy cows. J. Anim. Sci. 80:68-78.

Herva, T., A. Huuskonen, A.-M. Virtala, and O. Peltoniemi. 2011. On-farm welfare and carcass fat score of bulls at slaughter. Livest. Sci. 138:159-166.

Hoedemaker, M., D. Prange, and Y. Gundelach. 2009. Body condition change ante- and postpartum, health and reproductive performance in German Holstein cows. Reprod. Domest. Anim. 44:167-173.

ICAR (International Committee for Animal Recording). 2012. International Agreement of Recording Practices. Guidelines approved by the General Assembly held in Cork, Ireland on June 2012. ICAR, Rome, Italy.

Knierim, U., and C. Winckler. 2009. On-farm welfare assessment in cattle: Validity, reliability and feasibility issues and future perspectives with special regard to the Welfare Quality approach. Anim. Welf. 18:451-458.

Lievaart, J. J., and J. P. T. M. Noordhuizen. 2011. Ranking experts preferences regarding measures and methods of assessment of welfare in dairy herds using Adaptive Conjoint Analysis. J. Dairy Sci. 94:3420-3427.

Machado, V. S., L. S. Caixeta, J. A. A. McArt, and R. C. Bicalho. 2010. The effect of claw horn disruption lesions and body condition score at dry-off on survivability, reproductive performance, and milk production in the subsequent lactation. J. Dairy Sci. 93:4071-4078.

Martin, P., and P. Bateson. 1993. Measuring Behaviour: An Introductory Guide. Cambridge University Press, Cambridge, UK.

McCullagh, P., and J. A. Nelder. 1989. Generalized Linear Models. Chapman and Hall, London, UK.

Mülleder, C., J. Troxler, G. Laaha, and S. Waiblinger. 2007. Can environmental variables replace some animal-based parameters in welfare assessment of dairy cows? Anim. Welf. 16:153-156.

Nyman, A.-K., A. Lindberg, and C. H. Sandgren. 2011. Can precollected register data be used to identify dairy herds with good cattle welfare? Acta Vet. Scand. 53(Suppl. 1):S8.

Peeler, E. J., M. J. Otte, and R. J. Esslemont. 1994. Interrelationships of periparturient diseases in dairy cows. Vet. Rec. 134:129-132.

Phillips, C. J. C., and M. I. Rind. 2002. The effects of social dominance on the production and behavior of grazing dairy cows offered forage supplements. J. Dairy Sci. 85:51-59.

Plesch, G., N. Broerkens, S. Laister, C. Winckler, and U. Knierim. 2010. Reliability and feasibility of selected measures concerning resting behaviour for the on-farm welfare assessment in dairy cows. Appl. Anim. Behav. Sci. 126:19-26.

Roche, J. R., N. C. Friggens, J. K. Kay, M. W. Fisher, K. J. Stafford, and D. P. Berry. 2009. Invited review: Body condition score and its association with dairy cow productivity, health, and welfare. J. Dairy Sci. 92:5769-5801. 
Roche, J. R., J. M. Lee, K. A. Macdonald, and D. P. Berry. 2007a. Relationships among body condition score, body weight, and milk production variables in pasture-based dairy cows. J. Dairy Sci. 90:3802-3815.

Roche, J. R., K. A. Macdonald, C. R. Burke, J. M. Lee, and D. P. Berry. 2007b. Associations among body condition score, body weight, and reproductive performance in seasonal-calving dairy cattle. J. Dairy Sci. 90:376-391.

Rushen, J., A. M. de Passillé, and L. Munksgaard. 1999. Fear of people by cows and effects on milk yield, behavior, and heart rate at milking. J. Dairy Sci. 82:720-727.

Sandgren, C. H., A. Lindberg, and L. J. Keeling. 2009. Using a national dairy database to identify herds with poor welfare. Anim. Welf. 18:523-532.

SPSS Inc. 2010. IBM SPSS Statistics. Version 19.0.0.1. SPSS Inc., Chicago, IL.

Steiger Burgos, M., M. Senn, F. Sutter, M. Kreuzer, and W. Langhans. 2001. Effect of water restriction on feeding and metabolism in dairy cows. Am. J. Physiol. 280:R418-R427.

Val-Laillet, D., A. M. de Passillé, J. Rushen, and M. A. G. von Keyserlingk. 2008. The concept of social dominance and the social distribution of feeding-related displacements between cows. Appl. Anim. Behav. Sci. 111:158-172.

von Keyserlingk, M. A. G., D. Olenick, and D. M. Weary. 2008. Acute behavioral effects of regrouping dairy cows. J. Dairy Sci. 91:10111016.
VSN International Ltd. 2011. GenStat for Windows. Release 14. VSN International Ltd., Hemel Hempstead, UK.

Waiblinger, S., C. Menke, and G. Coleman. 2002. The relationship between attitudes, personal characteristics and behaviour of stockpeople and subsequent behaviour and production of dairy cows. Appl. Anim. Behav. Sci. 79:195-219.

Waiblinger, S., C. Menke, and D. W. Fölsch. 2003. Influences on the avoidance and approach behaviour of dairy cows towards humans on 35 farms. Appl. Anim. Behav. Sci. 84:23-39.

Webster, A. J. F., D. C. J. Main, and H. R. Whay. 2004. Welfare assessment: Indices from clinical observation. Anim. Welf. 13(Suppl. 1):S93-S98.

Welfare Quality. 2009. Welfare Quality ${ }^{\circledR}$ Assessment Protocol for Cattle. Welfare Quality ${ }^{\circledR}$ Consortium, Lelystad, Netherlands.

Wemelsfelder, F. 2007. How animals communicate quality of life: The qualitative assessment of behaviour. Anim. Welf. 16(Suppl. 1):25-31.

Whay, H. R., D. C. J. Main, L. E. Green, and A. J. F. Webster. 2003 Animal-based measures for the assessment of welfare state of dairy cattle, pigs and laying hens: Consensus of expert opinion. Anim. Welf. 12:205-217. 
APPENDIX

Table A1. Significance of predictors ${ }^{1,2}$ used in the final multivariable logistic regression models for prediction of a severe problem for dairy cattle welfare indicators ${ }^{3}$

Dairy cattle welfare indicator (response variable) ${ }^{4}$

\begin{tabular}{|c|c|c|c|c|c|c|c|c|c|c|c|c|c|c|c|c|c|c|c|c|c|}
\hline Predictor & QBI & $\begin{array}{l}\text { Freq. of } \\
\text { head } \\
\text { butts } \\
\text { (/cow } \\
\text { per h) }\end{array}$ & $\begin{array}{l}\text { Freq. of } \\
\text { displ. } \\
\text { (/cow } \\
\text { per h) }\end{array}$ & $\begin{array}{l}\text { Mean } \\
\text { time } \\
\text { to lie } \\
\text { down } \\
(\mathrm{s})\end{array}$ & CWS & LOLA & DHL & DU & DHQ & ND & Diar. & VD & Dyst. & VL & ML & SL & HP & $\mathrm{L} / \mathrm{S}$ & $\begin{array}{c}\text { No. } \\
\text { (length) } \\
\text { of } \\
\text { drinkers }\end{array}$ & $\underset{\text { drinkers }}{\geq 2}$ & $\begin{array}{l}\text { DYS } \\
(\%)\end{array}$ \\
\hline $\begin{array}{l}\text { Identification and registration } \\
\text { Herd size (no. of cows) }\end{array}$ & & & & & & & & & & & & & & & & & & & & & \\
\hline Change in herd size $(\%)$ & & & & & & $n^{*}$ & & & & & & & & & & $\mathrm{p}^{*}$ & & & & $\mathrm{n}^{* * *}$ & \\
\hline Replacement (\%) & & & & & & & & & & & & & & $\mathrm{p}^{*}$ & & & & & & $\mathrm{n} \dagger$ & \\
\hline Slaughter (\%) & & & & & & & & & & & & & & & & & & & & & \\
\hline $\begin{array}{l}\text { Slaughter <210 DIM } \\
\text { (yes/no) }\end{array}$ & & & & & & & & & & & & & & & & & & & & & \\
\hline On-farm mortality of cattle & & & & & & & & & & & & & & & & & & & & & \\
\hline Aged 0-3 d (\%) & & & & & & & & & & & & & & & & & & & & & \\
\hline Aged 4 d-1 yr (\%) & & & & & & & & & & & & & $\mathrm{n}^{*}$ & & & & & & & & \\
\hline Aged $>2$ yr $(\%)$ & & & & & & & & & & & & & & & & & & & & & \\
\hline $\begin{array}{l}0-60 \text { DIM (\%) } \\
60-120 \text { DIM }\end{array}$ & & $\mathrm{p} \dagger$ & & $n *$ & $\mathrm{p} \dagger$ & & & $\mathrm{n}^{*}$ & & $\mathrm{p}^{*}$ & & $\mathrm{p} \dagger$ & & $\mathrm{p}^{*}$ & & $\mathrm{p} \dagger$ & & & $\mathrm{p}^{*}$ & & \\
\hline $120-210$ DIM & & & $\mathrm{n}^{*}$ & & $\mathrm{p}^{*}$ & & & & & & & & & $\mathrm{n}^{* *}$ & & $\mathrm{p}^{*}$ & $\mathrm{n} \dagger$ & & & & \\
\hline$>210$ DIM & & & & $\mathrm{p}^{*}$ & & & & & & & & & & & $\mathrm{p}^{*}$ & & & $\mathrm{p}^{*}$ & & & \\
\hline $\begin{array}{l}\text { Average age }(\mathrm{mo}) \\
\text { Cows aged }>5 \text { yr }(\%)\end{array}$ & $(\uparrow, \uparrow)$ & $(\uparrow, \uparrow)$ & & & & $\mathrm{n}^{*}$ & & & & $\mathrm{n} * *$ & & $\mathrm{n}^{*}$ & & & & & $(\sim+)$ & & & & \\
\hline Cows 0-60 DIM (\%) & & & & & & & & & & $\mathrm{n}^{* *}$ & & & & & & & & & & & \\
\hline Management & & & & & & & & & & & & & & & & & & & & & \\
\hline Tie-stall (vs. loose housed) & $\mathrm{n}^{*}$ & & & & & & & & & & & & & & & & & & & & \\
\hline Zero-grazing (vs. pasture) & & & & & & & & & & & & & & & & $\mathrm{p} \dagger$ & & $\mathrm{p}^{*}$ & & & \\
\hline $\begin{array}{l}\text { Herd biosecurity status } \\
\text { (open/closed) }\end{array}$ & & & & & & & & & & & & & & & & & & & & & \\
\hline Certified disease-free status & & & & & & & & & & & & & & & & & & & & & \\
\hline $\mathrm{BVD}^{5}$ & & & $\mathrm{p}^{*}$ & $\mathrm{p}^{*}$ & $\mathrm{n} \dagger$ & & & & & & $\mathrm{p}^{*}$ & $\mathrm{n}^{*}$ & & & & & & & & & \\
\hline $\begin{array}{l}\text { IBR }^{\circ} \\
\text { Salmonella }\end{array}$ & & & & & & & & & & & & $\mathrm{p}^{*}$ & & & & & & & & & \\
\hline $\begin{array}{l}\text { Salmonella } \\
\text { Milk production }\end{array}$ & & & & & & & & & & & & & $\mathrm{n} \dagger$ & & $\mathrm{n}^{*}$ & & & & & & \\
\hline Average yield/cow per day & & & & & & & & $(\dagger, *)$ & $\mathrm{n}^{*}$ & & & & & & & & & & & & \\
\hline$(\mathrm{kg})$ & & & & & & & & & & & & & & & & & & & & & \\
\hline Net result $(€)$ & & & & & & & & & & & & & & & & & & & & & \\
\hline Change in net result (\%) & & & & & & & $\mathrm{n}^{*}$ & & & & $\mathrm{n} \dagger$ & & & & & & & & & & \\
\hline Average DIM & & & & & & & $\mathrm{p}^{*}$ & & & & & & & & & $(\dagger, \dagger)$ & & $(*, *)$ & & & \\
\hline $\begin{array}{l}\text { Milk composition } \\
\text { Average fat }(\%)\end{array}$ & & & & & & & & & & & & & & & & & & & & & \\
\hline $\begin{array}{l}\text { Average fat }(\%) \\
\text { Average protein }(\%)\end{array}$ & $(\dagger, \dagger)$ & $\mathrm{p} \dagger$ & & $\mathrm{p}^{*}$ & & $(\uparrow, \uparrow)$ & & & & & $\mathrm{nt}$ & & & $\left({ }^{*},{ }^{*}\right)$ & & & & & & & $\mathrm{p}^{*}$ \\
\hline Average fat/protein & $(*, *)$ & & & & & & & $\mathrm{p} \dagger$ & & & & & & & & $\mathrm{p}^{*}$ & & $(\dagger, \dagger)$ & & & \\
\hline $\begin{array}{l}\text { of cows } 0-60 \text { DIM } \\
\text { Average urea }(\%)\end{array}$ & $\mathrm{p}^{*}$ & & & $\mathrm{p}^{*}$ & & $n^{*}$ & & & & $\mathrm{nt}$ & & $\mathrm{n}^{*}$ & & & & & & $n^{*}$ & & & \\
\hline Butyric acid bacteria (yes) & & $\mathrm{p} \dagger$ & & & & & & & & III & & & & & & & & & & & \\
\hline FFA (mmol/100 g) & & & & $\mathrm{n} \dagger$ & & & & & & $\mathrm{n} \dagger$ & & & & & & & & & $\mathrm{n} \dagger$ & & \\
\hline Bulk milk SCC (cells/mL) & & & & & & $\mathrm{p} \dagger$ & & & & & & & & & & & & & & & \\
\hline Udder infection (\%) & & & & & & & & & & & & & & & & & & & & & $\mathrm{n}^{* * *}$ \\
\hline New udder infection (\%) & & & & $\mathrm{p}^{* *}$ & & & & & $\mathrm{p}^{* *}$ & & & & & & & & & & & & \\
\hline
\end{tabular}




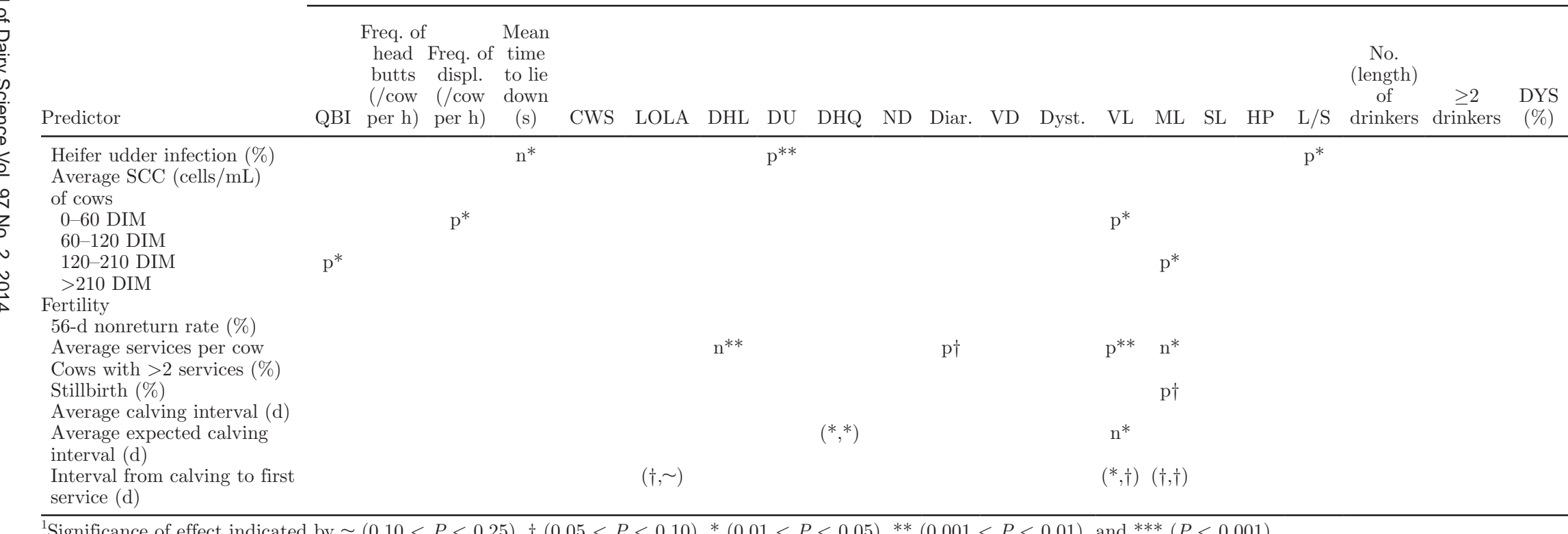

Direction of effect is indicated by "n" for a negative effect, "p" for a positive effect, and in parentheses (significance of linear term, significance of quadratic term) for a nonlinear

${ }^{3}$ Significance of effects not shown for the index for avoidance distance at the feeding rack because the final regression model was not significant.

${ }^{4}$ Units are the percentage of cows, unless otherwise noted. QBI = qualitative behavior index; Freq. = frequency; displ. = displacements; CWS $=$ colliding with stall; LOLA $=$ lying outside lying area; DHL = dirty hind legs; DU = dirty udder; DHQ = dirty hindquarters; ND = nasal discharge; Diar = diarrhea; VD = vulvar discharge; Dyst. = dystocia; VL = very lean; $\mathrm{ML}=$ moderately lame; $\mathrm{SL}=$ severely lame; $\mathrm{HP}=$ hairless patches; $\mathrm{L} / \mathrm{S}=$ lesions/swelling; $\mathrm{DYS}=$ dehorned young stock.

${ }^{5}$ Bovine viral diarrhea.

${ }^{6}$ Infectious bovine rhinotracheitis. 